\title{
Ruptured Rudimentary Horn Pregnancy: Two Case Reports
}

\author{
IRIN PARVEEN ALAM ${ }^{1}$, MAHBUBA ${ }^{2}$, QUORRTA EYNUL FORHAD 3
}

\begin{abstract}
:
Unicornuate uterus with rudimentary horn occurs due to failure of complete development of one Mullerian duct and incomplete fusion of the contralateral side. Pregnancy in rudimentary horn is rare and carries grave consequences to both mother and fetus. Here two case reports have been presented, both the cases were diagnosed after laparotomy. Diagnosis before rupture is challenging. So high index clinical suspicion and role of ultrasonography, resuscitation and laparotomy is necessary to prevent catastrophe.
\end{abstract}

Key word: Rudimentary horn pregnancy, ruptured ectopic pregnancy

\section{Introduction:}

Mullerian duct anomalies in female result from fusion or defective absorption during embryonic life. Prevalence of uterine anomalies is 1:200 to 1:600 in fertile women. Rudimentary horn is rarest uterine anomaly. Prevalence of unicornuate uterus with rudimentary horn is $1: 1,00,000$. The majority (up to $92 \%)$ of rudimentary horn are non communicating ${ }^{1}$. Pregnancy in rudimentary horn is the condition where the implantation occurs in the cavity of a rudimentary horn of a bicornuate uterus.Pregnancy in rudimentary horn is $1: 76,000 \& 1: 1,40,000$ pregnancies $^{2}$. Diagnosis prior to rupture occurs in as little as $14 \%$ of cases by ultrasonography ${ }^{3}$.

\section{Case Report 1:}

A 25-year-old, G3P1A1 with 16 weeks of pregnancy was referred to the Obstetric and Gynae emergency ward from medicine unit of Faridpur Medical College Hospital. The lady had a previous uneventful home delivery at full term about 10 years back and an abortion at 8 weeks about 7 years back. She was suffering from secondary subfertility for 6 years. She was not in antenatal check-up and had no ultrasonography done before her admission. But she often noticed lower abdominal pain. At her $16^{+}$weeks of pregnancy, she developed sudden severe lancinating lower abdominal pain starting from lower abdomen then spreading all over the abdomen. She was advised USG of lower abdomen from medicine ward and findings were that of ruptured ectopic pregnancy then she was referred to labour emergency. On examination, the lady was in hypovolemic shock with severe pallor and rapid thready pulse. Her blood pressure was $70 / 40 \mathrm{mmHg}$. The abdomen was tense and distended and the size of uterus could not made out. Pelvic examination revealed extreme paleness of vagina and fullness in the fornices with cervical movement tenderness. There was no per vaginal bleeding. As the patient was in shock, she was taken for immediate laparotomy with resuscitation. On opening the abdomen, the peritoneal cavity was filled with huge amount of fresh and clotted blood. There was bicornuate uterus with a rudimentary horn on the left side which was ruptured \& it was non-communicating. A male fetus was found in the peritoneal cavity and the cord with placenta was attached with ruptured rudimentary horn. (Figure-1). The right cornu of the uterus was normal in size with tube and ovary. The ruptured rudimentary horn with attached left tube was resected by placing double clamp at its base. Peroperatively, the patient received 3 units of whole blood. Her post-operative period was uneventful and she was discharged on $5^{\text {th }}$ post-operative day in good condition.

1. Assistant Prof Obstetrics \& Gynae, Sir Salimullah Medical College \& Mitford Hospital, Dhaka.

2. Associate Prof \& Head Of Gynae and Obstetrics, Faridpur Medical College Hospital, Faridpur,

3. Associate Prof Obstetrics \& Gynae, Shahabuddin Medical College Hospital, Dhaka. 


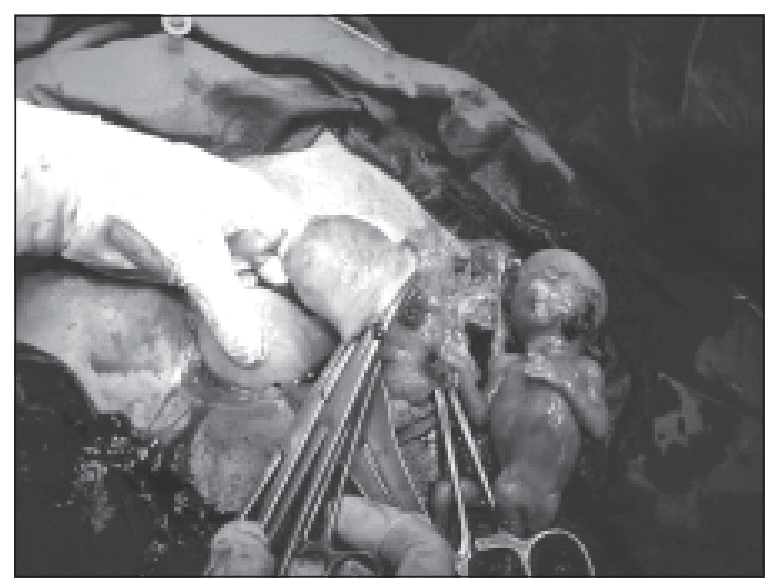

Fig.-1: (First Case)

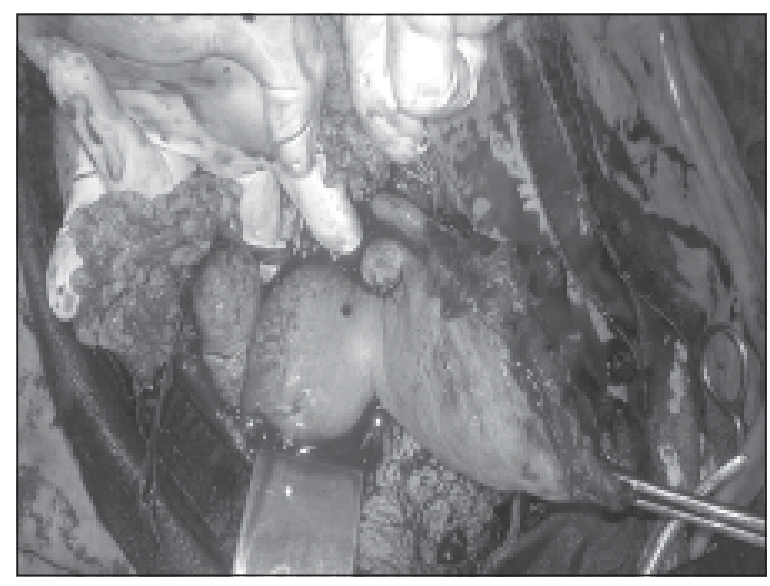

Fig.-2: (Second Case)

\section{Case Report 2}

A 20-year-old primi patient at her 19 weeks of pregnancy was referred to the Obstetric and Gynae emergency ward of Sir Salimullah Medical College \& Mitford Hospital. The lady was married for 2 years, and she had history of cyclical severe dysmenorhoea since her menarche. She was in regular antenatal check up. At her 19 weeks of pregnancy she developed sudden lower abdominal pain and it was gradually increasing in intensity, it was associated with slight pervaginal bleeding. Her ultrasonography, which was done two days prior to admission, shows 19 weeks missed abortion with placenta previa with a fibroid uterus. On examination patient was anaemic and had abdominal distension. She had signs of internal haemorrhage, again urgent ultrasonography was done and it showed ruptured ectopic pregnancy with a fetus of about 20 weeks. It was suspected clinically as a case of ruptured cornual pregnancy. Immediate resuscitation and laparotomy was done. During laparotomy there was huge amount of free blood and fetus was found outside the uterus (Fig-3) with placenta attached to the ruptured uterus. Uterus was bicornuate with one ovary and a tube attached to each horn. (Fig-2). Rupture was found at left rudimentary non-communicating horn and it was resected and left sided salphingectomy was done. Three bags of blood were transfused peropratively. Postoperative period was uneventful.

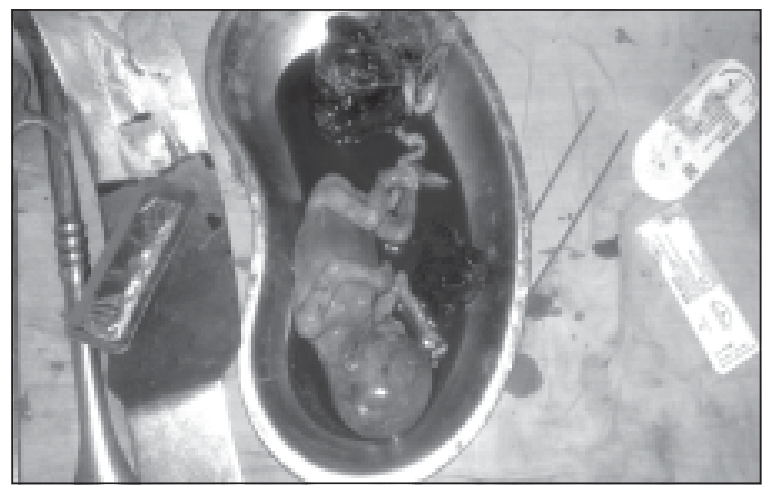

Fig.-3: Fetus in second case.

\section{Discussion:}

Unicornuate uterus with rudimentary horn occurs due to failure of complete development of one of the Mullerian ducts and incomplete fusion with the contralateral side. Pregnancy in a rudimentary horn is rare and occurs most commonlyin a noncommunicating horn. The only possible explanation for pregnancy to occur in this case is by transperitoneal migration of spermatozoa or fertilized ova through the contralateral tube. ${ }^{4}$ Unicornuate uterus with rudimentary horn may be associated with gynecological and obstetric complications. The diagnosis of cornual pregnancy is dependent on the quality of ultrasound and the skills of the investigator. Pregnancy in a non-communicating rudimentary horn usually terminates in rupture during first or second trimester of pregnancy. It usually ruptures later than tubal pregnancies because the myometrium is more distensible than the fallopian tube. It is very rare to reach a full term of a rudimentary horn pregnancy, though some literature shows $10 \%$ pregnancy reaches full term and foetal survival rate was $2 \% .{ }^{5}$ Rupture of the horn does not usually take place until $12-20^{\text {th }}$ week depending on the horn musculature and its ability of hypertrophy and distensibility. The rudimentary horn pregnancies in most of the cases are associated with catastrophic outcome. Every effort should be made to diagnose them at an early gestation. A detailed 
history should be taken from every patient on her first visit including any complaints of severe dysmenorhoea. However, the rudimentary horn may be underdeveloped and if its endometrium is non-functional and dysmenorrhoea may be absent. A careful pelvic examination in the first trimester showing deviated uterus with a palpable adnexal mass should arouse suspicion of a Mullerian anomaly. ${ }^{6}$.Ultrasound, hysterosalpingogram, hysteroscopy, laparoscopy, and MRI are the diagnostic tools ${ }^{7}$. It can be confirmed by an ultrasound examination in expert hand.The enlarging horn with thinned myometrium can obscure the adjacent anatomic structures and the sensitivity of ultrasonography decreases as the gestational age increases.When ruptured, bleeding is severe with massive intraperitoneal haemorrhage. Rudimentary horn pregnancy often can be complicated by placenta percreta due to the poorly developed musculature. Our $2^{\text {nd }}$ case was also associated with placenta accrete. This was confirmed after laparotomy. MRI has proven to be a very useful tool for the diagnosis of pregnancy with a Mullerian anomaly and to confirm the presence of placenta percreta. ${ }^{8}$ Smolders et al ${ }^{9}$ diagnosed RHP using MRI in a patient known to have a unicornuate uterus and a rudimentary horn by laparoscopy earlier. In our $2^{\text {nd }}$ case, the patient's earlier scans missed the diagnosis. It shows 20 weeks pregnancy with a fibroid uterus, which was actually a rudimentary horn pregnancy. Ultrasonography, which was done after rupture reported as rupture ectopic pregnancy with a fetus of about 20 weeks. So clinically it was suspected as cornual pregnancy and diagnosis was confirmed only after laparotomy.

The differential diagnosis of sonographically suspected RHPare tubal pregnancy, cornual pregnancy, and an intrauterine pregnancy in a bicornuate uterus. A tubal pregnancy will not show a ring of myometrium surrounding the gestational sac, but the differentiation between cornual, intrauterine pregnancy in a bicornuate uterus and RHPmay be difficult. Variation in thickness of the myometrium in 2 horns and a marked distance between them favor the diagnosis of a RHP. ${ }^{10}$ In contrast to RHP, continuity between the endometrial lining with the gestational sac and the other uterine horn is typical for a pregnancy in a bicornuate uterus. Tsafrir et al suggested the following criteria for early sonographic diagnosis of RHP:(1) pseudo pattern of an asymmetrical bicornuate uterus, (2)absent visual continuity between the cervical canal and the lumen of the pregnant horn, and (3) the presence of myometrial tissue surrounding the gestational sac ${ }^{11}$. Cornual ectopic or interstitial pregnancy is a rare form of ectopic pregnancy that implants and develops in the intrauterine portion of fallopian tube. The eccentric position of the gestational sac with an empty uterine cavity and the presence of a thin (less than $5 \mathrm{~mm}$ ) or even absent myometrium surrounding the sac are highly suggestive of cornual ectopic pregnancy on transvaginal sonography. The diagnosis may be helped with the use of Doppler studies showing increase vasculature often as a ring around the gestational sac. At experienced hands, trans-vaginal ultrasound can establish diagnosis of cornual ectopic in nearly $71 \%$ of cases. ${ }^{12}$

The traditional treatment of RHP is laparotomy and surgical removal of the pregnant horn to prevent rupture and recurrent RHP. Surgical removal is indicated as soon as diagnosis is made even before the patient is pregnant. Recently several cases of RHP were treated by laparoscopy using various techniques. ${ }^{13}$. Dicker et $\mathrm{al}^{14}$ removed a small rudimentary horn through the supra-pubic port. Edelman et al treated an RHP in a non-communicating horn by Methotrexate and Misoprostol. However, the patient underwent surgery 6 months later to remove the rudimentary horn, which contained degenerative tissue. ${ }^{15}$

\section{Conclusion:}

Rudimentary horn pregnancy in most cases are associated with a severe catastrophe. These are often incidentally diagnosed. Clinical suspicion, ultrasonography at expert hand and lastly MRI can confirm the diagnosis. Every effort should be made to diagnose the case early before the catastrophe.

\section{References:}

1. Johansen K. Pregnancy in a rudimentary horn. Obstet Gynecol 1983;61:565-7.

2. Daskalakis G, Pilalis A, Lykeridou K, Antsaklis A. Rupture of Noncommunicating Rudimentary Uterine Horn Pregnancy. Obstet Gynecol. 2002;100(5): 110801110

3. Jaya SingheY, Rane A, Stalewski H, Gover S .The presentation and early diagnosis of the rudimentary uterine horn. Obstetrics \& Gynecology2005;105:1456-67

4. M. Scholtz, "A full-time pregnancy in a rudimentary horn of the uterus," British Journal of Obstetrics \& Gynaecology, 1951. 58: 293-296. 
5. Pal K, Majumdar S, Mukhopadhyay S. Rupture of rudimentary uterine horn pregnancy at 37 weeks gestation with fetal survival. Arch Gynecol Obstet 2006;274:325-6.

6. Jain R, Gami N, Puri M, Trivedi SS. A rare case of intact rudimentary horn pregnancy presenting as hemoperitoneum. J Hum Reprod Sci 2010;3:113-115.

7. B. P. Lawhon, J. R.Wax, and R. T. Dufort, "Rudimentary uterine horn pregnancy diagnosed with magnetic resonance imaging," Obstetrics and Gynecology:1998; 91: 869

8. Leyendecker JR, Gorengaut V, Brown JJ. MR imaging of maternal diseases of the abdomen and pelvis during pregnancy and the immediate postpartum period. Radiographics 2004; 24:1301-16.

9. Smolders D, Deckers F, Pouillon M, Vanderheyden T, Vanderheyden J, De Schepper A. Ectopic pregnancy within a rudimentary horn in a case of unicornuate uterus. Eur Radiol 2002; 12:121-124.

10. Kriplani A, Relan S, Mittal S, Buckshee K. Prerupture diagnosis and management of rudimentary horn pregnancy in the first trimester. Eur J Obstet Gynecol Reprod Biol 1995; 58:203-205.

11. Tsafrir, N. Rojansky, H. Y. Sela, J. M. Gomori, and M. Nadjari, "Rudimentary horn pregnancy: first-trimester prerupture sonographic diagnosis and confirmation by magnetic resonance imaging," Journal of Ultrasound in Medicine 2005; 24(2): 219-223.

12. Abraham D, \& Silkowski C. Emergency Medicine Sonography 1st ed; 2010, 264-27

13. Falcone T, Gidwani G, Paraiso M, Beverly C, Goldberg J. Anatomical variation in the rudimentary horns of a unicornuate uterus: implications for laparoscopic surgery. Hum Reprod 1997; 12:263-265.

14. Dicker D, Nitke S, Shoenfeld A, Fish B, Meizner I, Ben-Rafael Z. Laparoscopic management of rudimentary horn pregnancy. Hum Reprod 1998; 13:2643-2644

15. Edelman AB, Jensen JT, Lee DM, Nichols MD. Successful medical abortion of a pregnancy within a noncommunicating rudimentary uterine horn. Am J Obstet Gynecol 2003; 189:886-887. 